\title{
Elimination of contamination in loop-mediated isothermal amplification assay for detection of human malaria
}

\author{
Zen, L.P.Y. ${ }^{1}$, Lai, M.Y. ${ }^{1}$ and Lau, Y.L. ${ }^{*}$ \\ ${ }^{1}$ Department of Parasitology, Faculty of Medicine, University of Malaya, 50603 Kuala Lumpur, Malaysia \\ *Corresponding author e-mail: lauyeeling@um.edu.my \\ Received 21 February 2020; received in revised form 10 August 2020; accepted 10 August 2020
}

\begin{abstract}
The LAMP assay, amplifies the target DNA rapidly, with 10-fold greater sensitivity than conventional PCR. The greater sensitivity also comes with greater risks of contamination. To overcome this issue, the current project includes either uracil DNA glycosylase (UDG) or a mineral oil overlay in the LAMP assay. Our results indicated that UDG or a mineral oil overlay can effectively prevent carryover contamination in the LAMP assay for the detection of human malaria. By incorporating these preventative methods, contamination can be eliminated and LAMP can potentially be used in the field; and point of care diagnosis for human malaria.
\end{abstract}

\section{INTRODUCTION}

Diagnosis of malaria is usually done by either microscopy, rapid diagnosis test and/or molecular methods. Microscopy technique remains the gold standard for the laboratory confirmation of malaria but it requires considerable expertise to prepare and view the blood smear. Molecular methods are often used in research due to its adaptability and versatility. LAMP assay has become a favourable and effective alternative as a molecular diagnostic tool in the recent years (Yang et al., 2018). Due to the multiple primers, the LAMP assay is more selective when amplifying target DNA sequences. The LAMP assay amplifies the target DNA in less than 60 minutes, with 10 -fold greater sensitivity than conventional PCR (Khan et al., 2018). The greater sensitivity also comes with greater risks of contamination. Previous publications have shown that carryover contamination is an imminent issue in molecular methods (Khan et al., 2018; Yang et $a l .$, 2018). Carryover contamination is the phenomenon in which amplified DNA products from previous reactions become templates for re-amplification that lead to false positive results (Hsieh et al., 2014). Whereas, cross contamination is the phenomenon in which DNA templates are unintentionally transferred from one assay to another. Due to this, there are precautions that could be taken both pre- and postamplification methods developed to prevent both types of contamination.

UDG is an enzyme that recognises and removes uracil residues that are generated by spontaneous deamination of cytosine residues in double-stranded DNA as a component of excision-repair processes (Schormann et al., 2014). By substituting deoxythymidine triphosphate (dTTP) with deoxyuridine triphosphate (dUTP) in the LAMP assay, the amplification products generated will have DNA containing dUTP. This makes the products that may contribute to carry over contamination susceptible to hydrolysis by the UDG enzyme.

The use of mineral oil to prevent cross contamination has been implemented in many PCR protocols (Kuipers et al., 1991; Bjourson et al., 1992). A mineral oil overlay acts as a barrier against cross contamination 
when preparing a molecular assay. The addition of DNA template into the oil layer drastically reduces the risks of aerosol formation, and therefore, reduces the contamination with DNA template (Snounou et al., 2002). In this study, the aim is to show that both uracil DNA glycosylase (UDG) and mineral oil is a good addition to LAMP assay in preventing contamination.

\section{MATERIALS AND METHODS}

\section{UDG-LAMP}

The LAMP assay and primers were referenced from Lau et al. (2016) with minor modifications. The dTTP was replaced with a dUTP and UDG enzyme (New England Biolabs, Ipswich, MA) was added. Malaria blood culture samples were obtained from the Department of Parasitology, Faculty of Medicine, University of Malaya. DNA was extracted using the DNeasy ${ }^{\circledR}$ Blood and Tissue Kit (Qiagen, Hilden, Germany). Postamplified LAMP product was serial diluted to $1 \times 10^{-13} \mathrm{~g}$ and $1 \mu \mathrm{L}$ of the diluted products was used as the DNA template respectively. The reaction tubes were incubated at room temperature $\left(25^{\circ} \mathrm{C}\right)$ for 5 minutes to allow the activation of UDG enzyme in the reaction. The reaction tubes were then incubated in Loopamp Real time turbidimeter LA 500 (Eiken Chemical Co., Ltd. Japan) for 1 hour at $65^{\circ} \mathrm{C}$ followed by $80^{\circ} \mathrm{C}, 2$ minutes. These experiments were repeated six times in the same lab.

\section{LAMP with mineral oil overlay}

In this study, we also tested the effectiveness of mineral oil in preventing carryover contamination. To create the scenario of carryover contamination in mineral oil experiment, two separate sets of LAMP assay were conducted. The first set of LAMP assay consisted of three reaction tubes. Reaction tube 1 contained LAMP reaction mix and $P$. knowlesi DNA only, reaction tube 2 contained LAMP reaction mix and $P$. knowlesi DNA with an overlay of $10 \mu \mathrm{L}$ mineral oil and reaction tube 3 was a negative control with $\mathrm{ddH}_{2} \mathrm{O}$ as template. The LAMP assays were incubated at $65^{\circ} \mathrm{C}$ for 1 hour and $80^{\circ} \mathrm{C}$ for 2 minutes in turbidity meter. The results of set 1 must show positive amplification in reaction tube 1 ( $P$. knowlesi DNA) and reaction tube 2 (P. knowlesi DNA overlaid with mineral oil); and show negative amplification in reaction tube $3\left(\mathrm{ddH}_{2} \mathrm{O}\right)$ in order to proceed to the following step.

The cap of reaction tube 1 from the first set of LAMP assay was opened during the preparation of the second set of LAMP assays and was left for another 10 minutes after the preparation. Set 2 of LAMP assays consisted of $P$. knowlesi DNA sample (A1) and a negative control with ddH2O (A2) respectively, followed by incubation at $65^{\circ} \mathrm{C}$ for 1 hour and $80^{\circ} \mathrm{C}$ for 2 minutes in turbidity meter. Similarly the tube 2 from set 1 was opened in close proximity during and after the preparation of the LAMP assays which consisted of $P$. knowlesi DNA sample (A7) and a negative control (A8). The experiments were repeated three times in the same lab.

\section{RESULTS AND DISCUSSIONS}

In Figure 1, the reaction tube A1 with diluted positive LAMP product from previous amplification, uracil DNA glycosylase and $P$. knowlesi DNA template showed positive amplification at 51 minutes. The reaction tube A2 with diluted positive LAMP product and uracil DNA glycosylase without $P$. knowlesi DNA was negative. Meanwhile, the reaction tube A3 with diluted LAMP product from previous amplification without uracil DNA glycosylase and without new $P$. knowlesi DNA was positive at 35 minutes (A3). A negative control (A4) with doubledistilled water $\left(\mathrm{ddH}_{2} \mathrm{O}\right)$ as template was negative.

The addition of this enzyme to the LAMP reaction mixture allows selective hydrolysis and removal of previously amplified products without affecting the DNA template in the LAMP assay. The LAMP reaction is incubated at room temperature $\left(25^{\circ} \mathrm{C}\right)$ for 5 minutes to hydrolyze and remove any amplified products from previous amplifications before the optimal temperature of LAMP at $65^{\circ} \mathrm{C}$. UDG enzyme has the inactivation temperature of $50^{\circ} \mathrm{C}$. Therefore, the sub- 


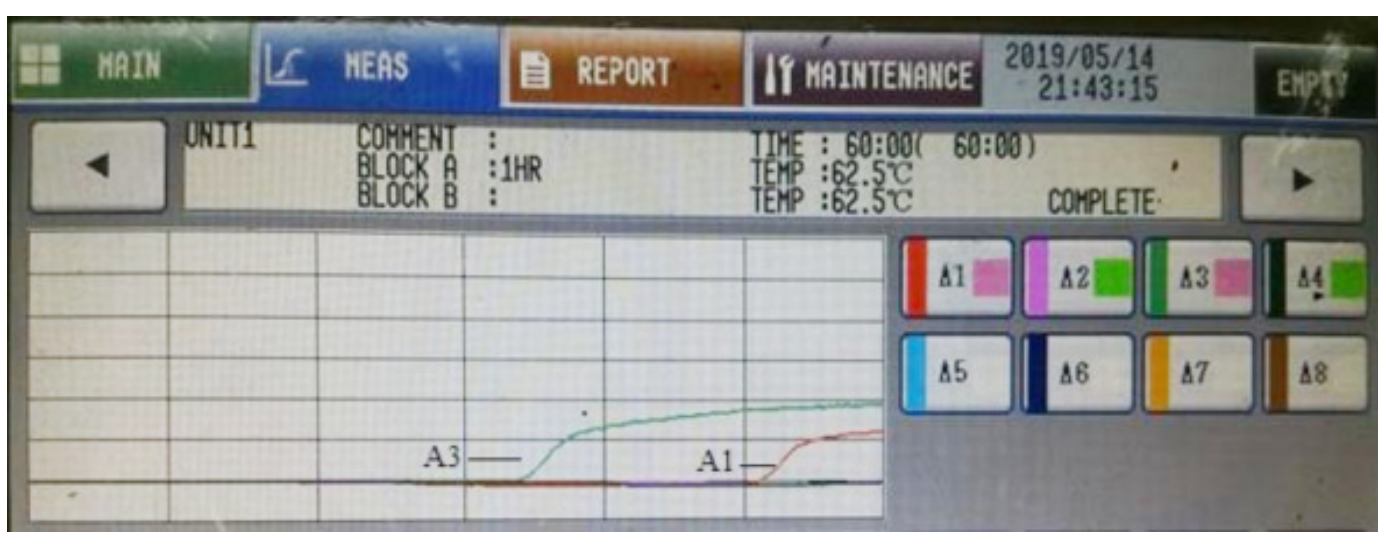

Figure 1. Simulated carryover contamination for UDG-LAMP. Each partition on the horizontal axis was represented as 10 minutes whereas the partition on the vertical axis was represented as 0.1 in turbidity. A1: LAMP product $\left(0.6 \times 10^{-13} \mathrm{~g}\right)$, Uracil DNA glycosylase, $P$. knowlesi DNA; A2: LAMP product $\left(0.6 \times 10^{-13} \mathrm{~g}\right)$, Uracil DNA glycosylase; A3: LAMP product $\left(0.6 \times 10^{-13} \mathrm{~g}\right) ; \mathrm{A} 4: \mathrm{ddH}_{2} \mathrm{O}$ (no target control).

sequent incubation of the reaction tubes at $65^{\circ} \mathrm{C}$ effectively inactivates the UDG enzyme and allowing the LAMP reaction to proceed.

Tang et al. (2016) has reported a UDGreal-time reverse transcription (rRT)-LAMP method for detection of Tembusu virus. LAMP amplicons were serial diluted with concentrations ranging from $0.5 \times 10^{-19}$ to $0.5 \times 10^{-14} \mathrm{~g} / \mu \mathrm{L}$, where it was found that rRT-LAMP without UDG can detect as little as $1 \times 10^{-18} \mathrm{~g}$ of simulated carryover contamination per reaction and showed that the addition of UDG can eliminate as much as $1 \times 10^{-16} \mathrm{~g} /$ per reaction of contaminants.

LAMP products are concatemers in which its' concentration is difficult to quantify (Subramanian et al., 2019), therefore the concentration of LAMP products were calculated based on the webinar, LoopMediated Isothermal Amplification (LAMP): Assay Development Challenges and Solutions published by Lucigen (Middleton, WI). According to Lucigen (2019), the typical yield of product is estimated to be 10-20 $\mu \mathrm{g}$ in one LAMP reaction mixture of $25 \mu \mathrm{L}$. End product of LAMP was known to contribute the aerosol contamination to air once the cap of reaction tube was opened. Movement of people around the lab also contributed to the contamination in air. Assuming the LAMP product yielded $15 \mu \mathrm{g}$ in a total reaction of $25 \mu \mathrm{L}$, the concentration of the LAMP product is $0.6 \times 10^{-6} \mathrm{~g} / \mathrm{\mu L}$. Subsequently, a 10 -fold serial dilution was carried out for 10 times to achieve $0.6 \times 10^{-16} \mathrm{~g} / \mu \mathrm{L}$. Following the optimization, it was found that the UDG enzyme incorporated with the LAMP reaction was able to eliminate contaminants up to $0.6 \times 10^{-13} \mathrm{~g}$ in this study. A McNemar's Test was conducted using IBM SPSS v23 to determine the significance of the addition of UDG in a LAMP assay compromised by carryover contamination. The $\mathrm{P}$ value was determined to be 0.031 , making it statistical significant when $\mathrm{P}<0.05$.

In Figure 2, the reaction tube with $P$. knowlesi DNA (A1 in Figure 2) and with $\mathrm{ddH}_{2} \mathrm{O}$ only (A2 in Figure 2) which were prepared in close proximity with LAMP reaction tube 1 from set 1 containing LAMP positive LAMP product without an overlay of mineral oil were both positive. Meanwhile, the reaction tube with $P$. knowlesi DNA (A7 in Figure 2) was positive and the reaction tube with $\mathrm{ddH}_{2} \mathrm{O}$ only (A8 in Figure 2) was negative, when both of these LAMP reactions were prepared in close proximity with LAMP reaction tube 2 from set 1 containing positive LAMP product with an overlay of mineral oil. From the results of this experiment one would not be able to distinguish whether the contamination was due to cross or carryover contamination. However, we can observe that a mineral oil overlay was able to prevent the contamination. 


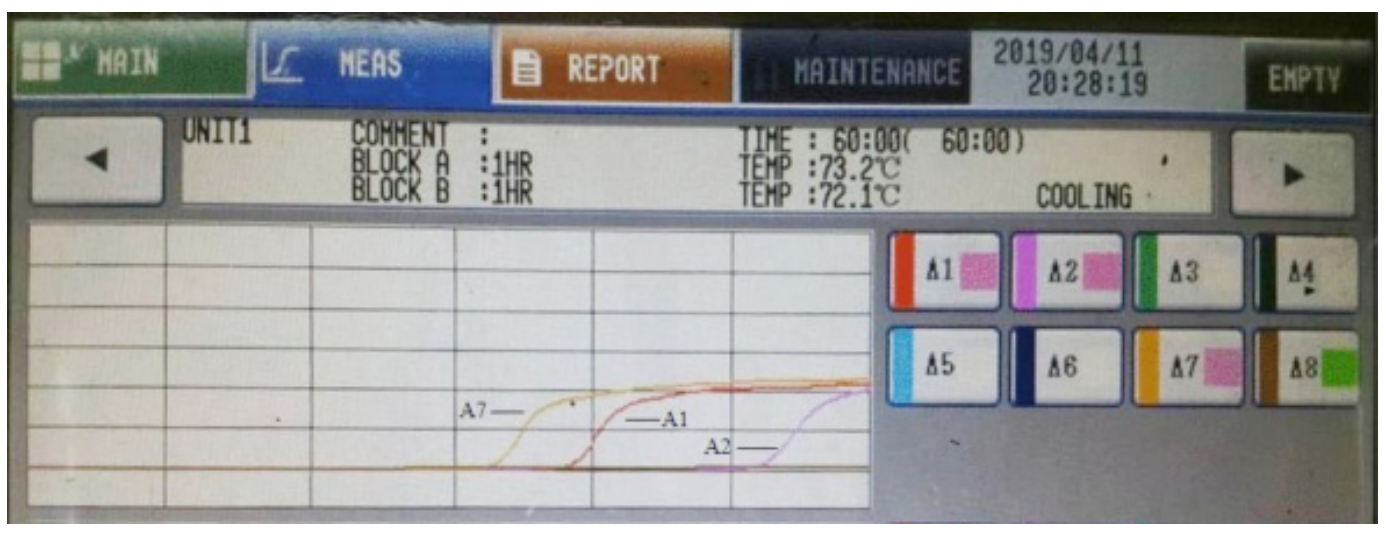

Figure 2. Simulated scenario of carryover contamination in mineral oil-LAMP. The assays exposed to LAMP products without mineral oil are A1: P. knowlesi DNA; A2: $\mathrm{ddH}_{2} \mathrm{O}$ (no target control). The assays exposed to LAMP products with mineral oil are A7: P. knowlesi DNA; A8: $\mathrm{ddH}_{2} \mathrm{O}$ (no target control).

In the case of carryover contamination, it is seen to be less desirable if the LAMP reaction tube is not meant to be a one pot, closed vessel, reaction mixture that is able to be qualitatively observed. If an agarose gel electrophoresis is still required in order for the results to be viewed from the amplification, the risk of aerosols is still present, especially when using an incubator which lacks a heating lid on the top to prevent sample evaporation. As shown in Figure 2 mineral oil did in fact prove to be a good barrier against carryover contamination compared to the absence of it. To exhibit a mechanical barrier during the experiments, the subsequent LAMP master mix preparation were done in two separates labs for the LAMP reaction mixtures with mineral oil and the LAMP reactions without mineral oil respectively. Loading DNA template in the layer of oil and allowing the DNA to merge with the reaction mixture requires a certain degree of precision (Snounou et al., 2002). The difference in volume of mineral oil was also observed in different protocols ranging from $10 \mu \mathrm{L}, 50 \mu \mathrm{L}$ and $100 \mu \mathrm{L}$ (Kuipers et al., 1991; Snounou et al., 2002; Tien et al., 2018). In this study, $10 \mu \mathrm{L}$ of mineral oil is able to act as a good barrier in preventing the LAMP product from vaporizing into the atmosphere.

\section{CONCLUSION}

When preparing a LAMP assay for the diagnosis of human malaria, additions of both mineral oil, uracil DNA glycosylase and deoxyuridine triphosphate should highly be taken into consideration to reduce false positives. By incorporating these preventative methods, contamination can be eliminated and LAMP can potentially be used in the field; and point of care diagnosis for human malaria.

Acknowledgements. This project was financially supported by Long Term Research Grant Scheme (LRGS), LR002D-2018 from the Ministry of Education, Malaysia.

\section{Conflict of Interest}

The authors declare that they have no conflict of interest.

\section{REFERENCES}

Bjourson, A.J. \& Cooper, J.E. (1992). Bandstab PCR: a simple technique for the purification of individual PCR products. Nucleic Acids Research 10: 4675. 
Hsieh, K., Mage, P.L., Csordas, A.T., Eisenstein, M. \& Soh, H.T. (2014). Simultaneous elimination of carryover contamination and detection of DNA with uracil-DNAglycosylase-supplemented loop-mediated isothermal amplification (UDG-LAMP). Chemical Communications 50: 37473749.

Khan, M., Wang, R., Li, B., Liu, P., Weng, Q. \& Chen, Q. (2018). Comparative evaluation of the LAMP assay and PCR-based assays for the rapid detection of Alternaria solani. Frontiers in Microbiology $\mathbf{9}$ : 2089.

Kuipers, O.P., Boot, H.J. \& de Vos, W.M. (1991). Improved site-directed mutagenesis method using PCR. Nucleic Acids Research 19: 4558.

Lau, Y.L., Lai, M.Y., Fong, M.Y., Jelip, J. \& Mahmud, R. (2016). Loop-mediated isothermal amplification assay for identification of five human Plasmodium species in Malaysia. American Journal Tropical Medicine and Hygiene 94: 336-339.

Schormann, N., Ricciardi, R. \& Chattopadhyay, D. (2014). Uracil-DNA glycosylasesstructural and functional perspectives on an essential family of DNA repair enzymes. Protein Science 23: 1667-1685.
Snounou, G. \& Singh, B. (2002). Nested PCR analysis of Plasmodium parasites. In: Malaria methods and protocols, Doolan, D.L. (editor). New Jersey: Humana Press, pp.189-204

Subramanian, S. \& Gomez, R. (2019). An empirical approach for quantifying loopmediated isothermal amplification (LAMP) using Escherichia coli as a model system. PLoS One 9: 6

Tang, Y., Chen, H. \& Diao, Y. (2016). Advanced uracil DNA glycosylase-supplemented real-time reverse transcription loopmediated isothermal amplification (UDG-rRT-LAMP) method for universal and specific detection of Tembusu virus. Scientific Reports 6: 27605.

Tian, X., Feng, J. \& Wang, Y. (2018). Direct loop-mediated isothermal amplification assay for on-site detection of Staphylococcus aureus. FEMS Microbiology Letters 365: fny092.

Yang, Q., Domesle, K.J. \& Ge, B. (2018). Loopmediated isothermal amplification for Salmonella detection in food and feed: current applications and future directions. Foodborne Pathogens and Disease 15: 309-331. 